\title{
Sorafenib Improves Survival in Metastatic Hepatocellular Carcinoma: A Case Report
}

\author{
Filipe Nerya, ${ }^{\mathrm{a}}$, Luis Graca ${ }^{\mathrm{b}}$, Manuel Ribeiro ${ }^{\mathrm{c}}$, Henrique Guimaraes ${ }^{\mathrm{c}}$, \\ Helena Pessegueiro Miranda ${ }^{a}$
}

\begin{abstract}
Hepatocellular carcinoma (HCC) is a very common cancer. Curative treatments and local ones are well validated. Sorafenib, a multikinase receptor inhibitor was introduced in 2007 for advanced HCC in patients with preserved liver function. $\mathrm{HCC}$ is known to be resistant to systemic chemotherapy, and there are no validated therapies improving survival for metastatic disease. Herein, we report a case of a 45 years old woman with chronic hepatitis B infection submitted to a right hepatectomy in May 2001 for an hepatic tumor with more than $10 \mathrm{~cm}$ wide, confirmed as a HCC moderately differentiated. Three years later, a solitary pulmonary metastasis was documented and a metastectomy was done. In February 2009, the patient started on sorafenib $400 \mathrm{mg}$ twice daily due to an inferior mediastinal metastasis with a vena cava thrombus associated. Computed tomography (CT) scan done 13 months after revealed a consistently mass reduction in more than $50 \%$ and a clinically well patient without important collateral effects. HCC is a highly vascularized tumor and sorafenib is known to inhibit both tumor angiogenesis and tumor cell survival. It is already approved for the treatment of advanced and metastatic renal cell cancer. In our case, the combination of two well done surgical procedures and the posterior use of sorafenib when a metastasis was found in an inaccessible surgical place with macroscopic vascular invasion, led to a long survival without important side effects.
\end{abstract}

Keywords: Hepatocellular carcinoma; Metastatic disease; Sorafenib

Manuscript accepted for publication September 2, 2010

${ }^{a}$ Internal Medicine Department, Centro Hospitalar do Porto - Hospital Santo Antonio, Portugal

${ }^{\mathrm{b}}$ Surgical Department, Centro Hospitalar do Porto - Hospital Santo Antonio, Portugal

${ }^{\mathrm{c}}$ Radiology Department, Centro Hospitalar do Porto - Hospital Santo

Antonio, Portugal

${ }^{\mathrm{d}}$ Corresponding author, Email: filipegaionery@gmail.com

doi:10.4021/wjon240w

\section{Introduction}

Liver cancer is the sixth most common cancer all over the world, which is consistently the third most common cause of cancer death in recent years, with a very heterogeneous distribution worldwide depending on the etiology of the subjacent chronic liver disease $[1,2]$. In Portugal, the incidence of hepatocellular carcinoma (HCC) is rising, with a mortality rate that affects a quarter of HCC hospital admission [3].

Clinical, radiologic, biochemical and cytological diagnostic HCC criteria are well recognized and reproducible, and treatment modalities vary according to tumor dimension, number of nodules, localization, liver function and subjacent cirrhosis, disseminated disease, and local resources. Surgical treatment has a curative aim, varying from tumor resection with free margins to liver transplantation. In MELD (Model for End-Stage Liver Disease) era, for allocating patients in a waiting liver transplantation list, a change was necessarily made to those with HCC (as it may arise in patients with normal or nearly-normal liver function with a low MELD score putting them in a low position for transplantation) $[4,5]$. Depending on the centers, Milan criteria or more extended ones as San Francisco are used to incorporate patients in a waiting list for transplantation according to survival expectancy $[6$, 7].

Local HCC treatments exist as neo-adjuvant or downstaging options, including trans-arterial chemo-embolisation, radio-frequency ablation, percutaneous ethanol injection and trans-arterial radioembolisation, with the aim of reducing tumor dimension and serving as a bridge to surgical resection or transplantation [8].

Increased expression of multidrug resistance transporters and active intracellular metabolism in HCC results in an intrinsic resistance to chemotherapy drugs, conducing systemic chemotherapy as to be historically ineffective [9-11].

Successive stages of liver damage, from fibrosis to cirrhosis and HCC, depend on formation of new vessels and the establishment of an abnormal angioarchitecture. It seems that platelet-derived growth factor (PDGF), transforming growth factor-b1 (TGF-b1), fibroblast growth factor (FGF) and vascular endothelial growth factor (VEGF) play a potent 
pro-fibrogenic and pro-angiogenic role in liver disease [12]. It was based on this relationship between angiogenesis and HCC that sorafenib, an oral multi-targeted tyrosine kinase inhibitor (of Raf-1, VEGFR2 and 3, PDGFR- $\beta$, FLT3 and KIT), was considered as a promising therapy and approved in 2007 for the treatment of advanced HCC. By competing with adenosine triphosphate (ATP) for the ATP-binding site of the catalytic domain of the tyrosine kinase, sorafenib prevents the intracellular signaling which leads to angiogenesis $[13,14]$.

Sorafenib was sequentially involved in phase I, II and III studies [15-17]. A survival advantage of nearly 3 months was proved in a phase III study that compared patients with advanced HCC under sorafenib versus placebo, confirmed by a more recent meta-analysis, and changing the way how to treat these patients $[17,18]$.

Recently, 15 cases of complete remission attributed to sorafenib treatment in HCC with extrahepatic spread were reported in Japan though it is rarely reported in other countries, even because there is no clear indication on the use of sorafenib in this kind of patients [19].

We report a clinical case of a patient with chronic hepatitis B infection with metastatic HCC disease controlled with sorafenib treatment.

\section{Case Report}

In May 2001, a 45-year-old woman was referred to our center due to a liver mass. She had chronic hepatitis B, diag- nosed in 1997 after routine blood test. No viral treatment was done. In May 2001, due to abdominal pain localized at right hypochondria, an abdominal ultrasound was done, which revealed a mass with $10 \mathrm{~cm}$ wide in the posterior segments of the right hepatic lobe, and the patient was referred to our center. Computed tomography (CT) abdominal scan confirmed a hypodense mass with peripheral contrast enhancement in arterial phase with portal washout, highly suggestible of a HCC. AgHbs, AntiHbc and AntiHbe were positive. Delta virus was negative, as was hepatitis $\mathrm{C}$ virus and HIV1/2. Liver analysis revealed an AST of $155 \mathrm{U} / \mathrm{L}, \mathrm{ALT}$ of $192 \mathrm{U} / \mathrm{L}, \mathrm{PAL}$ of $130 \mathrm{U} / \mathrm{L}, \mathrm{GGT}$ of $170 \mathrm{U} / \mathrm{L}$ and $\alpha$-fetoprotein (AFP) of $60.77 \mu \mathrm{g} / \mathrm{L}$. The HBV DNA was negative. Coagulation was normal. Her ECOG performance status was 1 and Karnofsky performance status scale of $90 \%$. As it was a unique mass in a non-cirrhotic liver (liver function was preserved and there were no signs of chronic liver disease in imagery), a right hepatectomy was performed. Histology revealed a moderately differentiated HCC with a size of $8 \times 10 \times 14 \mathrm{~cm}$ and a trabecular pattern with an immunocytochemistry revealing negativity for AFP and positivity for CAM 5.2. Remnant liver revealed a chronic hepatitis with mild fibrosis. Transaminases and AFP levels returned to normal values after surgery $(3.4 \mu \mathrm{g} / \mathrm{L})$. No antiviral therapy or any adjuvant systemic chemotherapy was started.

Three years later (May 2004), in a routine CT scan, a nodular lesion with $2 \mathrm{~cm}$ wide with tissue density in the right inferior pulmonary lobe was found. AFP levels were normal $(3.9 \mu \mathrm{g} / \mathrm{L})$. As it was a unique metastasis, a metastectomy was done. Histology was concordant with a HCC metastasis.

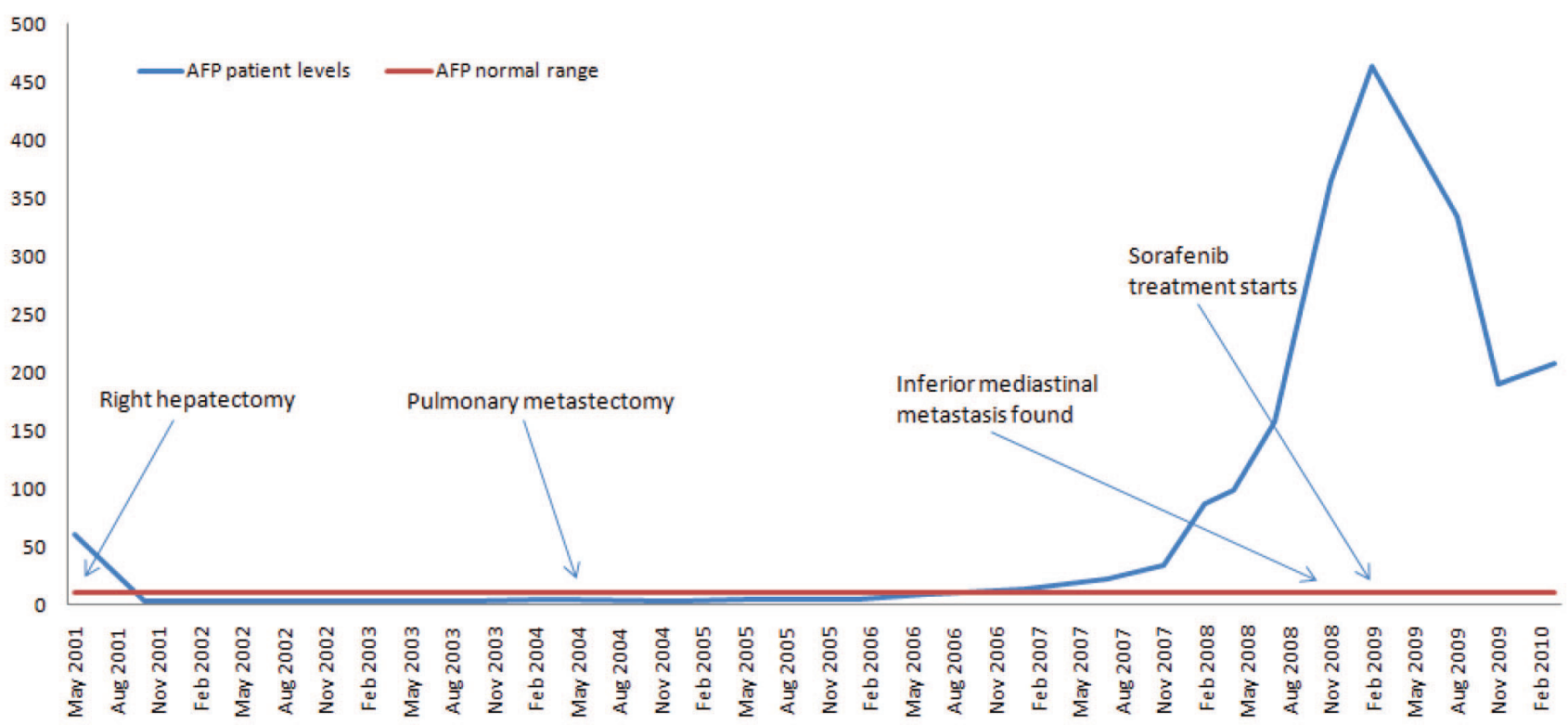

Figure 1. $\alpha-$ Fetoprotein evolution and principal events along the clinical course. 


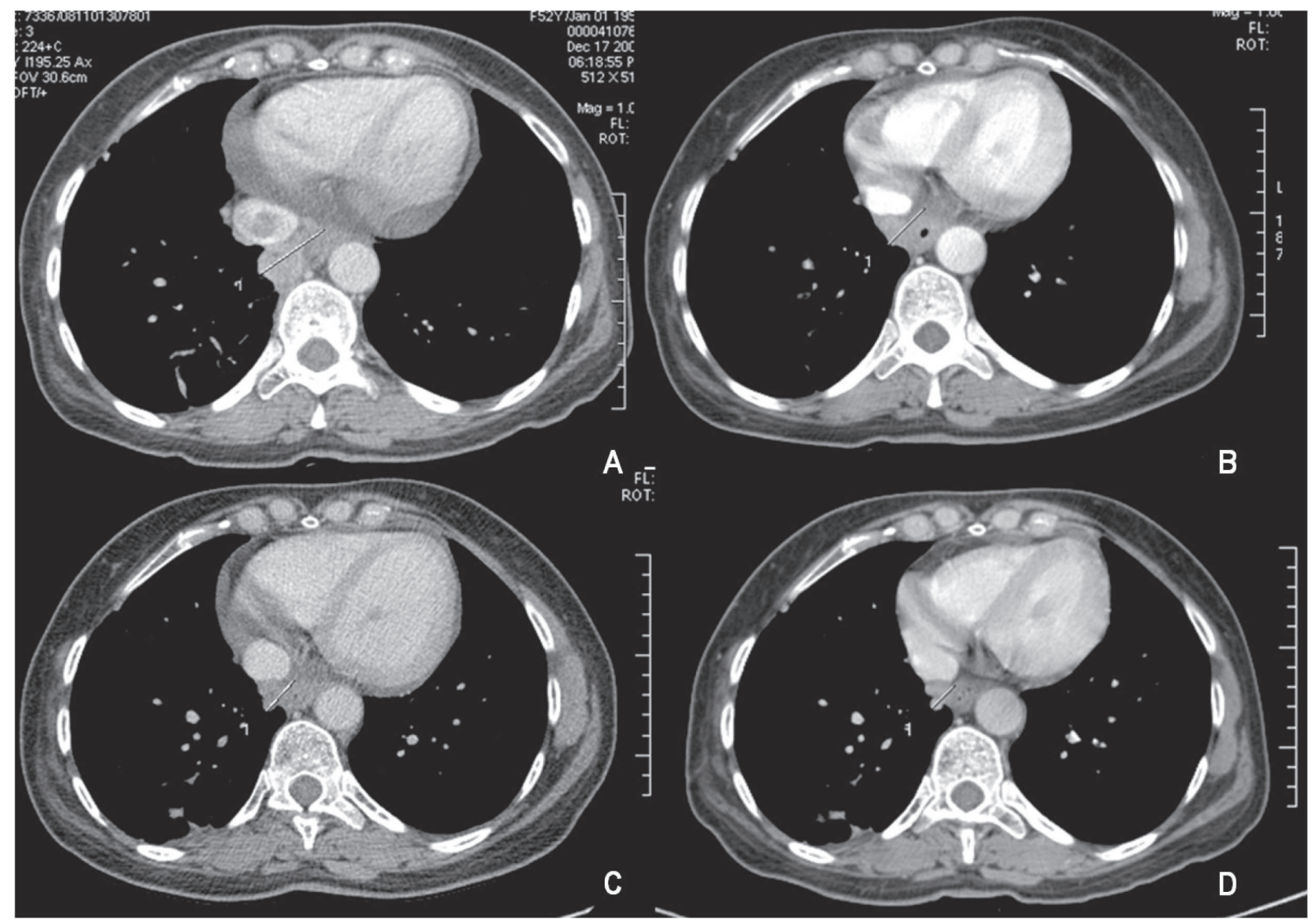

Figure 2. Mass involution under sorafenib treatment: (A) December 2008; (B) May 2009; (C) November 2009; (D) March 2010.

The patient remained under surveillance. In January 2007, AFP levels started slowly rising (Fig. 1). A more tightened program with regular thoracic and abdominal CT scans was started, all being negative for disseminated disease. In spite of its low sensitivity for HCC, a PET scan was done in July 2008, which was described as normal. At that time AFP was of $157.4 \mu \mathrm{g} / \mathrm{L}$, transaminases were normal and $\mathrm{HBV}$ DNA was of $2908 \mathrm{IU} / \mathrm{mL}$.

A rising AFP contrasted with the absence of demonstration of any tumor in repeatedly imaging techniques. In December 2008 , AFP peaked at $365.4 \mu \mathrm{g} / \mathrm{L}$. At that time, a dynamic CT identified an inferior mediastinal mass of $3.5 \times 3.3$ $\mathrm{cm}$ associated with a vena cava thrombus. Sorafenib $(400 \mathrm{mg}$ twice daily) was started in February 2009 (AFP of $464 \mu \mathrm{g} / \mathrm{L}$, DNA VHB of $7310 \mathrm{UI} / \mathrm{mL}$, normal transaminases) resulting in a decline of AFP values and a reduction of more than $50 \%$ of the metastatic mass (15 mm wide in March 2010) and of vena cava thrombus size (Fig. 2). Antiviral treatment with lamivudine $100 \mathrm{mg} /$ day was started simultaneously resulting in an undetectable HBV DNA 3 months after. The patient is asymptomatic, reporting only transitory hair loss during treatment.

\section{Discussion}

Our patient had a chronic hepatitis B infection, recognized in 1997 due to a disturbed hepatic profile, never treated, and a HCC that developed in a non-cirrhotic liver. HCC surveillance benefit is uncertain in this subpopulation of hepatitis B female carriers younger than 50 years old without cirrhosis [20]. In spite of that, surveillance strategies are well documented [21].

The HBV can cause HCC, directly by HBV DNA integration in the host genome and by persistent expression of viral proteins (such as HBx and LHBs: Large envelope protein) that are capable of oncogenes activation, inducing oxidative stress and genetic instability, or indirectly due to hepatocellular injury induced by chronic HBV infection and hepatocyte regeneration, conferring an annual incidence of HBV-related HCC in patients with chronic hepatitis B that ranges from $2 \%$ to $5 \%$ and with a lifetime risk for HCC approximately $10-25 \%[22,23]$. Our patient presented with an advanced disease, with a mass of more than $5 \mathrm{~cm}$ wide and cancer-related symptoms, conferring a dismal prognosis by the time of referral. Bigger tumors are less differentiated and 
a more common vascular and lymph invasion is expected, predisposing such patients to disseminated disease or recurrence.

As the patient had no evidence of cirrhosis and no macroscopic invasion of vascular structures, a right hepatectomy was performed as an intention to treat procedure.

By the time when the solitary pulmonary metastasis was found, metastectomy was made, as there was no evidence of liver relapse. Surgical resection of 1 or 2 solitary metastasis is recommended in the absence of intrahepatic HCC, improving survival [24].

Nowadays, AFP is not recommended for HCC surveillance, but it is recognized as a risk factor for HCC [25]. It was the rising of AFP during the follow-up that alerted the practitioner to a new probable metastasis elsewhere and made a change in the surveillance conduct. A metastasis was found in an inaccessible localization with a vena cava thrombus associated. At that time there was no place for surgical resection and systemic therapy was considered. As no systemic chemotherapy is recognized to improve survival in disseminated HCC, sorafenib was tried.

In our case, prolonged survival was related not only to a proper surgical approach (right hepatectomy and metastectomy) but also to the use of sorafenib, surpassing life expectancy at the beginning and by the time when metastatic disease was documented.

The patient is under sorafenib treatment since 17 months ago, who is clinically well, and with a documentation of more than 50\% tumor reduction revealed in a CT scan 13 months after sorafenib was started.

Hepatocellular carcinoma is a highly vascularized tumor. Sorafenib in known to inhibit both tumor angiogenesis (via VEGF and PDGF signaling) and tumor cell survival (RAF kinase signaling-dependent and signaling-independent mechanisms), and is already approved for the treatment of renal cell advanced and metastatic disease [26]. In Japan, its use in metastatic $\mathrm{HCC}$ in patients with preserved liver function (Child-Pugh A) is consensual [19]. Very few case reports in the western world document complete remission of HCC metastatic disease (both to the lung) [27, 28].

The protracted time course of the HCC in this patient was very uncommon. Sorafenib seems a very exciting therapy for advanced HCC, and may also have very important benefits in particular patients with metastatic HCC. Phase III studies in patients with HCC and metastatic disease should come out quickly to put sorafenib (or other molecule with the same properties) in this context in the everyday clinical field.

\section{References}

1. Parkin DM, Bray F, Ferlay J, Pisani P. Global cancer statistics, 2002. CA Cancer J Clin 2005;55(2):74-108.

2. Ferlay J, Shin HR, Bray F, Forman D, Mathers C, Parkin DM. Estimates of worldwide burden of cancer in 2008: GLOBOCAN 2008. Int J Cancer 2010.

3. Marinho RT, Giria J, Moura MC. Rising costs and hospital admissions for hepatocellular carcinoma in Portugal (1993-2005). World J Gastroenterol 2007;13(10):15221527.

4. Wiesner RH, McDiarmid SV, Kamath PS, Edwards EB, Malinchoc M, Kremers WK, Krom RA, et al. MELD and PELD: application of survival models to liver allocation. Liver Transpl 2001;7(7):567-580.

5. Vullierme MP, Paradis V, Chirica M, Castaing D, Belghiti J, Soubrane O, Barbare JC, et al. Hepatocellular carcinoma--what's new? J Visc Surg 2010;147(1):e1-12.

6. Mazzaferro V, Regalia E, Doci R, Andreola S, Pulvirenti A, Bozzetti F, Montalto F, et al. Liver transplantation for the treatment of small hepatocellular carcinomas in patients with cirrhosis. N Engl J Med 1996;334(11):693699.

7. Yao FY, Ferrell L, Bass NM, Bacchetti P, Ascher NL, Roberts JP. Liver transplantation for hepatocellular carcinoma: comparison of the proposed UCSF criteria with the Milan criteria and the Pittsburgh modified TNM criteria. Liver Transpl 2002;8(9):765-774.

8. Toso C, Mentha G, Kneteman NM, Majno P. The place of downstaging for hepatocellular carcinoma. J Hepatol 2010;52(6):930-936.

9. Jiang W, Lu Z, He Y, Diasio RB. Dihydropyrimidine dehydrogenase activity in hepatocellular carcinoma: implication in 5-fluorouracil-based chemotherapy. Clin Cancer Res 1997;3(3):395-399.

10. Chenivesse X, Franco D, Brechot C. MDR1 (multidrug resistance) gene expression in human primary liver cancer and cirrhosis. J Hepatol 1993;18(2):168-172.

11. Farmer DG, Rosove MH, Shaked A, Busuttil RW. Current treatment modalities for hepatocellular carcinoma. Ann Surg 1994;219(3):236-247.

12. Fernandez M, Semela D, Bruix J, Colle I, Pinzani M, Bosch J. Angiogenesis in liver disease. J Hepatol 2009;50(3):604-620.

13. Eichholz A, Merchant S, Gaya AM. Anti-angiogenesis therapies: their potential in cancer management. Onco Targets Ther 2010;3(69-82.

14. Robert SK. Tumor angiogenesis - Molecular origins of cancer. N Engl J Med 2008, 358(19): 2039-49

15. Strumberg D, Richly H, Hilger RA, Schleucher N, Korfee S, Tewes M, Faghih M, et al. Phase I clinical and pharmacokinetic study of the Novel Raf kinase and vascular endothelial growth factor receptor inhibitor BAY 43-9006 in patients with advanced refractory solid tumors. J Clin Oncol 2005;23(5):965-972.

16. Abou-Alfa GK, Schwartz L, Ricci S, Amadori D, Santoro A, Figer A, De Greve J, et al. Phase II study of 
sorafenib in patients with advanced hepatocellular carcinoma. J Clin Oncol 2006;24(26):4293-4300.

17. Llovet JM, Ricci S, Mazzaferro V, Hilgard P, Gane E, Blanc JF, de Oliveira AC, et al. Sorafenib in advanced hepatocellular carcinoma. N Engl J Med 2008;359(4):378390.

18. Zhang T, Ding X, Wei D, Cheng P, Su X, Liu H, Wang $\mathrm{D}$, et al. Sorafenib improves the survival of patients with advanced hepatocellular carcinoma: a meta-analysis of randomized trials. Anticancer Drugs 2010;21(3):326332.

19. Kudo M, Ueshima K. Positioning of a molecular-targeted agent, sorafenib, in the treatment algorithm for hepatocellular carcinoma and implication of many complete remission cases in Japan. Oncology 2010;78 Suppl 1(154-166.

20. Bruix J, Sherman M. Management of Hepatocellular Carcinoma: An Update. Hepatology 2010, 0(0):1-35 AASLD Practice Guideline

21. Colombo M. Screening and diagnosis of hepatocellular carcinoma. Liver Int 2009;29 Suppl 1(143-147.

22. Neuveut C, Wei Y, Buendia MA. Mechanisms of HBV- related hepatocarcinogenesis. J Hepatol 2010;52(4):594604.

23. Nguyen VT, Law MG, Dore GJ. Hepatitis B-related hepatocellular carcinoma: epidemiological characteristics and disease burden. J Viral Hepat 2009;16(7):453-463.

24. Chan KM, Yu MC, Wu TJ, Lee CF, Chen TC, Lee WC, Chen MF. Efficacy of surgical resection in management of isolated extrahepatic metastases of hepatocellular carcinoma. World J Gastroenterol 2009;15(43):5481-5488.

25. Sherman M. Serological surveillance for hepatocellular carcinoma: time to quit. J Hepatol 2010;52(4):614-615.

26. Albouy B, Gross Goupil M, Escudier B, Massard C. [Renal cell carcinoma management and therapies in 2010]. Bull Cancer 2010;97(17-28.

27. Yeganeh M, Finn RS, Saab S. Apparent remission of a solitary metastatic pulmonary lesion in a liver transplant recipient treated with sorafenib. Am J Transplant 2009;9(12):2851-2854.

28. So BJ, Bekaii-Saab T, Bloomston MA, Patel T. Complete clinical response of metastatic hepatocellular carcinoma to sorafenib in a patient with hemochromatosis: a case report. J Hematol Oncol 2008;1(18. 